\title{
Setting Health-Care Priorities: A REPLY TO TÄNNSJÖ
}

\author{
- Robert E. Goodin -
}

\begin{abstract}
This paper firstly distinguishes between principles of "global justice" that apply the same anywhere and everywhere - Tännsjö's utilitarianism, egalitarianism, prioritarianism and such like - and principles of "local justice" that apply within the specific sphere of health-care. Sometimes the latter might just be a special case of the former - but not always. Secondly, it discusses reasons, many psychological in nature, why physicians might devote excessive resources to prolonging life pointlessly, showing once again that those reasons might themselves be morally significant.
\end{abstract}

Keywords: health-care priorities, welfare consequentialism, local justice, medical anthropology, prolonging life pointlessly.

Published online: 1 August 2020

Let me begin with a couple of disclaimers. First, I am far from expert in medical ethics. My main exposure the subject came through a year-long fellowship in Bioethics at the US National Institutes of Health and through a series of ongoing co-authorships with an emergency physician whom I first met there. The physician, Chiara Lepora, came out of and went back into MSF, at one point administering its operations all across the Middle East. ${ }^{1}$ Although I have talked with her at great length about such matters, her window onto them is obviously very distinctive, and that may well color what I have to say in relation to Tännsjö's book. ${ }^{2}$

The second disclaimer is that my own formation, like Tännsjö's, is as an analytical philosopher and my basic philosophical predilections like his are welfare-consequentialistic. Insofar as I differ with him over the particular applications under discussion, those differences do not arise from any deep philosophical disagreement. I would characterize those differences as more "observational" than "principled," certainly at least in the first instance.

Robert E. Goodin

School of Philosophy

Australian National University

Canberra ACT 2601, Australia

e-mail: Bob.Goodin@anu.edu.au

${ }^{1}$ You can see her at work in a trailer for the prize-winning documentary, "Living in Emergency" MSF (2008). Our principal collaboration was Lepora and Goodin (2013), which was the subject of symposia in Criminal Law and Philosophy: Ratner, French, Lepora et al. (2016) and the Journal of Medical Ethics: Lepora, Goodin, Shue et al. (2017).

2 Tännsjö (2019). 


\section{Principles of Justice: Global or Local}

My deepest disagreement with Tännsjö might best be characterized as one between "global" and "local justice." By that I do not mean to refer to the argument between "nationalists" and "cosmopolitans" over what, if anything, the world's rich owe to the world's poor. Instead, I mean to pick up Michael Walzer's observation that there are "separate spheres of justice" within which distinctive distributive rules ${ }^{3}$ - what Jon Elster calls rules of "local justice" 4 - apply.

So what I am distinguishing between are principles of global justice that apply the same anywhere and everywhere - Tännsjö's utilitarianism, egalitarianism, prioritarianism and such like - and principles of local justice that apply within the specific sphere of health-care. I leave open for the moment what might the relation between those global and local principles, and whether the latter might just be a special case of the former (with a little more concrete empirical texture, or some such). I shall come back to that issue shortly.

\subsection{Some Principles of Local Health Care Justice}

First however let me try to tease out what some of the distinctive local-justice principles internal to the practice of health care realm might be.

1) Give priority for treatment to those medically most in need.

- Other things being equal, the most seriously injured or unwell should be treated first. Directing the flow of traffic according to that principle is the principal task of the triage nurse in the Emergency Room.

- In an "overload" situation, where need vastly outstrips treatment resources, assign priority on the basis of prognosis combined with need (so someone who is very badly injured but has little hope of recovery even with extensive treatment might be passed over in favour of someone a little less badly injured but with much better chances of recovery).

2) Give priority to the most urgent cases.

- That might just be part and parcel of the first principle, depending on how "medical need" is defined. But it might be a separate principle. E.g., you should arguably treat one person's broken leg before another person's cancer, even though the latter patient is in some sense medically in greater need (he will die of cancer, whereas an untreated broken leg will only lead to amputation).

- But again, in an overload situation where you are being constantly overwhelmed by urgent cases, you might carve out some resources to devote to treatment of chronic conditions, so that "acute care" does not swamp "chronic care." E.g., in my coauthor's MSF hospitals were in communities devastated by armed conflicts, which had led all other hospitals there to

\footnotetext{
${ }^{3}$ Walzer (1983).

${ }^{4}$ Elster (1990; 1992).
} 
close; the MSF hospitals took care (after a fashion) of all the "ordinary medical needs" (complications of childbirth and such like), alongside taking care of gunshot wounds arising from the conflict that occasioned their intervention. (That, incidentally, is why MSF workers find it so heart-wrenching to withdraw from a community once the conflict is over - they had providing all those other medical services the need for which will still remain after the conflict is over.)

3) Another principle is one of non-aband onment.

- Once you have commenced treatment, you must not cease treatment so long as it is still needed (unless the patient requests you to do so, or unless there is another physician who will take over treatment, or unless the prognosis is hopeless). Ordinarily, you do not cease caring for a less medically-needy patient, just because another more needy case arrives (although if the disparities are extreme, you might with apologies do so).

- Consider the analogy to the case of a Good Samaritan doctor, who (although not legally required to) stops at the scene of an accident. They were under no legal obligation to begin treatment of someone who has been injured; but once they have commenced treatment, they are legally obliged to continue treatment (at least until other help arrives). ${ }^{5}$

4) A final principle is that prevention is ordinarily better than cure.

- This may be a little more controversial within the health-care community. In effect, it prioritizes public health interventions over therapeutic medical ones; so professionals in the latter field may self-interestedly oppose it. But I cannot imagine any disinterested health policy-maker denying the validity of this as a general rule, to which there might be always be exceptions of course.

\subsection{Relating Local Principles to Global Ones}

One thought might be that local principles are just "localized" versions of global principles of justice. That is to say, they are just special applications of the basic global principles, adapted in light of the special circumstances of the health-care sphere. So let me now turn to consider how the local principles internal to the practice of medicine might relate to the global principles of justice around which Tännsjö orients his discussion.

- If egalitarianism in general implies levelling down, as Tännsjö accepts it does, then it would be just plain crazy to apply it in specifically health-care contexts. You don't give everyone polio just because some people have been killed or disabled by it.

- Leximin, specifically applied to health-care contexts, would imply prioritizing treatment to the medically worst off. Were "medically worst off" understood as "neediest" or "most urgent," then that would be precisely what my first two local principles require. But leximin ordinarily takes "worst off" to be

\footnotetext{
${ }^{5}$ Weinrib (1980): $276 \mathrm{ff}$.
} 
"worst off across the board, looking across all relevant dimensions of comparison." If "medically worst off" is understood in that way, it becomes wildly implausible. Should we treat one patient's sprained ankle before another's broken leg, just because the first is in worse health overall (e.g. has cancer, or even just bad asthma)? Surely not.

- Utilitarianism implies allocating medical resources where they would do most good. The global version of that principle would refer to "most good overall," across all relevant dimensions of assessment, not merely medical ones. But perhaps for present purposes we should restrict the scope of our utilitarianism to "doing the most good medically." That restricted utilitarian principle would track medical practice as regards triage in overload cases, where we take into account both a patient's medical need and prognosis. Such utilitarianism can also give us reasons (if only a contingent ones) for favouring prevention over cure, insofar as prevention is cheaper or more effective, or cure is only partial or involves a period of suffering that prevention could have avoided. But on the face of it, such utilitarianism fails to account for non-abandonment of chronic-care patients when medical facilities are swamped by acute cases. ${ }^{6}$

\section{Explaining the Temptation to Prolong Life Pointlessly}

Those more general points about the uneasy relations between "local" and "global" principles of justice can be further illuminated through more detailed discussion of the particular application upon which Tännsjö focuses, medical practices that pointlessly prolong life. Those might be regarded as a form of "local justice" in health care. Where do those local principles of justice pertaining to the prolongation of live come from? And how, if at all, can they be squared with more "global" principles of justice?

I share Tännsjö's sense that too many resources are devoted to prolonging life pointlessly for terminally ill patients. Of course not all such prolongation is pointless. There may be good reasons for someone to want to live just a little longer - to see their child married, to meet their new grandchild, to say farewell properly, to make amends to people they've hurt, to wrap up their affairs in an orderly manner, to finish writing their last novel. All those are good reasons to want to live just a little longer. ${ }^{7}$

Whether they are good enough reasons to justify hyperexpensive treatment that soaks up resources that would be better used elsewhere is a separate question. But at least there's a calculation to be made in such cases. So in my first two discussions below I'm going to focus on cases where prolonging life is literally pointless - not just in the sense that "they are going to die anyway" (that's true of all of us, young or old!), but

\footnotetext{
${ }^{6}$ Unless it can argue that there are so many more chronic cases than acute that more utility is achieved overall by treating rather than abandoning them for acute cases. It is an empirical question whether that is true in any given case; sometimes it will be, sometimes not. If we think that nonabandonment is always the right principle, utilitarianism will not give us that result. Conversely if we think utilitarianism is the right principle, non-abandonment will sometimes be wrong by those lights.

7 Gorovitz (1982): 153-154.
} 
in the sense that there is nothing in particular that they want to do with the extra days, weeks or months that the heroic measures would buy them. In my third discussion below I shall return to the case of those with "unfinished business."

The question I want to ask about all these cases is, at least in the first instance, less a philosopher's question than a medical anthropologist's question. ${ }^{8}$ I shall be less concerned with the question of whether morally we ought to accede to their requests, and more concerned with the question of why we do might actually so. ${ }^{9}$ In other words, I shall (in the first instance anyway) be attempting to explain - not justify - the practice of devoting substantial medical resources to the pointless prolongation of life. I see three possible reasons, which I shall address in turn.

\subsection{Squeaky Wheels}

Let me begin by discussing a partially analogous situation that arises with regard to disability-rights advocates. Disabilities are many and varied, of course. In places like Australia (and I'm guessing many places elsewhere too) there exist peak bodies responsible for advocating on behalf of the disabled to policymakers in both the public and private sectors. There are also community consultations seeking input from those affected by disability policies, presently or in prospect. Now, you can't help noticing one striking fact about the members of the disabled community who turn up at such events or sit on such peak bodies. They tend to be disproportionately young people whose disabilities put them in wheelchairs but leave them otherwise unscathed. They have very clear ideas about what should be done to ameliorate the difficulties they suffer - and of course they are right that all those things should be done, resources permitting. But insofar as these peak bodies or community consultations are supposed to be representing the perspectives of the disabled in general, one cannot help doubting that that particular subset of the disabled are really representing the views and needs of other subsets who are not present (the demented elderly, for example, or the severely cognitively impaired). Still, the wheelchair-bound disabled are the ones that turn up; and they are, in consequence, the "squeaky wheels" that get the proverbial oil.

My first suggestion is that one explanation for why too many resources are devoted to prolonging life pointlessly for terminally ill patients is that those patients are right in front of the attending physician, whereas others on whom those resources might be better spent may often not be. Take the people with whom both Tännsjö and the WHO think we should be more concerned: people who are suffering debilitating depression. ${ }^{10}$

\footnotetext{
${ }^{8}$ There are many types of medical anthropologists of course. The sort I am here aligning myself with are studies of "social mores" - of the rules and practices of a social group - as opposed to the sort of medical anthropologist who offers evocative stories of particular individuals in particular clinical encounters. An example of the former is Roth (1963) and of the latter is Biehl (2005).

${ }^{9}$ Many other causes of pointless prolongation of life have little or nothing to do with patients' expressed wishes. Among them are the socio-cultural environment, the training of health professionals, various institutional arrangements, financial interests, legal constraints, health insurance policies, media treatment and so on. See Kaufman (2015).

${ }^{10}$ WHO (2001).
} 
Many of them may be suffering in private in the community, and not be in contact with any medical service providers.

Given that the one group of medically needy people is physically present in the doctor's consulting rooms and is urgently petitioning for treatment (herself, or others are on her behalf), whereas other people who might be more cost-effectively treated using those same resources are not, it should come as no surprise that those who are present win out in the competition over those who are absent.

\subsection{Statistical versus Identifiable Lives}

The "squeaky wheel" explanation works more on the basis of pressure and lobbying power of patients who are physically present before the physician. There may be a connected explanation that works more through the conscience (or perhaps just the psychology) of the physician.

The conscience side of the story is just this. It is a cornerstone of medical ethics that "the physician's first and primary duty is to the patient."11 There are various ways of understanding that injunction: one is in terms of "her own patients" (as against all patients including those not her own); another is in terms of "this particular patient" (as against other patients, including some in that physician's own waiting room). On either of those understandings, however, that injunction of medical ethics would seem to enjoin the physician to devote resources to the patient (even the terminally-ill patient) before her that might be better spent on other patients (even some of her own). ${ }^{12}$

There is a psychological side to the story as well. Nobel Prize winning economist Thomas Schelling famously observed:

There is a distinction between individual life and a statistical life. Let a six-year-old girl with brown hair need thousands of dollars for an operation that will prolong her life until Christmas, and the post office will be swamped with nickels and dimes to save her. But let it be reported that without a sales tax the hospital facilities of Massachusetts will deteriorate and cause a barely perceptible increase in preventable deaths - not many will drop a tear or reach for their checkbooks. ${ }^{13}$

If it is correct ${ }^{14}$, then the physical presence of the terminally ill patient before the physician, combined with the fact that people (physicians included) value identifiable lives more than statistical lives, might explain why the physician spends more resources to prolong the lives of ill (even terminally ill) patients known to her than other patients not known to her.

\footnotetext{
11 ACP (2012): 86.

${ }^{12}$ I would argue that neither is the correct understanding of the injunction, but that is a separate issue: moral, not explanatory. See Goodin (2015). The UK National Institute for Health and Care Excellence similarly "recognizes that when it is making its decisions it should consider the needs of present and future patients of the NHS who are anonymous and who do not necessarily have people to argue their case on their behalf"; NICE (2008): 20-21.

${ }^{13}$ Schelling (1984): 115.

${ }^{14}$ Russell (2014).
} 
There may be an ethical thought underlying that psychological observation as well. It might be argued that individual people have a moral status - Kantian "dignity" or whatever ${ }^{15}$ - that sheer statistical artefacts do not. ${ }^{16}$ Connected to this might be the way in which many people think we should demand "individualized evidence" rather than accepting "statistical likelihood" as adequate for conviction in a criminal trial. ${ }^{17}$ People (physicians treating the terminally ill) might in such ways rationalize their psychological propensity to accord objectively disproportionate importance to those why are physically present before them compared to others unknown to them but who are equally real and arguably in as much need of the same health care resources.

\subsection{The Endpoint is Psychologically Special}

Psychological studies of people's memories of experiences and willingness to repeat them have consistently found that people place disproportionate weight on their experience of the endpoint. Here are some examples:

- One study involved experimental subjects holding their hand in a bowl of uncomfortably cold water. They did so twice. One time, they held their hand in the uncomfortably cold water for a minute and then removed it. The other time, they held their hand in a bowl of water at the same temperature for a minute, and then for an additional half-minute as the water gradually warmed by just one degree. Subjects were more willing to repeat the second experience than the first, even though it involved having their hand in uncomfortably cold water longer, because the situation was improving at the end. ${ }^{18}$

- Another study involved patients undergoing a colonoscopy, who were asked how much pain they were experiencing periodically throughout the procedure and how much pain they remembered after the procedure was over. Those who reported experiencing less pain in the last three minutes of the procedure were significantly more likely to remember the procedure as less painful overall, even when the total amount of pain they reported experiencing during the procedure is held statistically constant. Nobel Laureate Daniel Kahneman and his coauthor conclude that study with a recommendation to clinicians: "gradual relief may be preferable to abrupt relief if patients retain a less aversive memory when the intense pain does not occur near the end of the procedure."19

- In a final study, experimental subjects were asked to rate the desirability of different lives. They systematically rated a wonderful life that ended abruptly as much more desirable than one that tailed off at the end after a mid-life peak. They also systematically rated an unhappy life that started to get better at the end as more desirable than one that peaked in mid-life and tailed off at the end. ${ }^{20}$

\footnotetext{
${ }^{15}$ Waldron (2012).

${ }^{16}$ I would again argue that this is an incorrect understanding, since the statistical artifacts in question care comprised of people with just as strong dignitarian claims; but again, this is a separate (moral, rather than explanatory) issue.

17 Tribe (1971).

${ }^{18}$ Kahneman, Fredrickson, Schreiber et al. (1993).

${ }^{19}$ Redelmeier, Kahneman (1996): 7.

${ }^{20}$ Diener, Wirtz, Sishi (2001).
} 
Needless to say, that small sample of studies hardly constitutes a comprehensive account of how people perceive pain, but that was not my aim in introducing them anyway. All I wanted to do was to point out, through them, that people seem to set particularly (arguably irrationally) great store on the way that things end. What implications might that have for end-of-life decision-making?

First and foremost, it presumably argues for permitting voluntary euthanasia so people can die in relatively pleasant circumstances of their choosing. At the very least, it argues for palliative care to make the end as comfortable as possible.

But for some people - those who have a sense of "unfinished business" - it might entail prolonging their lives so they can finish that more satisfactorily before they die. Of course, prolonging life then wouldn't be "pointless," certainly not from their point of view; so this line of reasoning does not explain why some people seem to want what I have described as "pointless prolongation" of their lives or the lives of their loved ones. There are doubtless other deep psychological dynamics at work in those cases. But the particular psychological importance that people attach to endpoints, quite generally, might go some way toward explaining why the "unfinished business" rationale for desiring prolongation is so very strong.

\subsection{From Explaining to Justifying}

In all of those ways, then, the temptation to prolong life pointlessly seems perfectly explicable. All of those explanations point, in the end, to psychological reasons that may lead physicians to prefer to do so. But psychological explanation is one thing, moral justification another. Or is it? For welfare consequentialists such as Tännsjö and me, preference satisfaction is after all the coin of the realm. So the fact that physicians have those preferences must presumably count - not necessarily decisively, but nonetheless count - toward making them morally justifiable at least in the eyes of us welfare consequentialists.

\section{References}

American College of Physicians' Ethics, Professionalism and Human Rights Committee (ACP) (2012), "American College of Physicians Ethics Manual: Sixth Edition," Annals of Internal Medicine 156 (2): 73-104.

Biehl J.G. (2005), Vita: Life in a Zone of Social Abandonment, University of California Press, Berkeley.

Diener E., Wirtz D., Sishi S. (2001), “End Effects of Rated Life Quality: The James Dean Effect," Psychological Science 12: 124-128.

Elster J. (1990), “Local Justice," Archives Européenees de Sociologie 31: 117-140.

Elster J. (1992), Local Justice: How Institutions Allocate Scarce Goods and Necessary Burdens, Russell Sage Foundation, New York.

Goodin R.E. (2015), “The Collective Action Problem," [in:] Fair Priority Setting and Rationing at the Bedside, M. Danis, S. Hurst, A.M. Slowther et al. (eds.), Oxford University Press, Oxford: 224-237.

Gorovitz S. (1982), Doctors' Dilemmas: Moral Conflict and Medical Care, Oxford University Press, New York. 
Kahneman D., Fredrickson B.L., Schreiber C.A. et al. (1993), “When More Pain Is Preferred to Less: Adding a Better End," Psychological Science 4 (6): 401-405.

Kaufman S. (2015), Ordinary Medicine, Duke University Press, Durham, NC.

Lepora C., Goodin R.E. (2013), On Complicity and Compromise, Oxford University Press, Oxford.

Lepora C., Goodin R.E., Shue H. et al. (2017), "Symposium on On Complicity and Compromise," Journal of Medical Ethics 43 (4): 269-278.

Médecins Sans Frontières (MSF) (2008), "Living in Emergency,” URL=https:/ / www.youtube. $\mathrm{com} /$ watch? $\mathrm{v}=\mathrm{mM} 3 \mathrm{Na9a2mzw}$ [Accessed 30.06.2020].

National Institute for Health and Care Excellence (NICE) (2008), "Social Value Judgments: Principles for the Development of NICE Guidance," 2nd ed., NICE, London, URL= https:/ / www.ncbi.nlm.nih.gov/books/NBK395865/pdf/Bookshelf_NBK395865. pdf [Accessed 30.06.2020].

Ratner S.R., French P.A., Lepora C. et al. (2016), "Symposium on On Complicity and Compromise," Criminal Law and Philosophy 10 (3): 559-602.

Redelmeier D.A., Kahneman D. (1996), "Patients' Memories of Painful Medical Treatments: Real-Time and Retrospective Evaluations of Two Minimally Invasive Procedures," Pain 66 (1): 3-8.

Roth J. (1963), Timetables: Structuring the Passage of Time in Hospital Treatment and Other Careers, Bobbs-Merrill, Indianapolis.

Russell L.B. (2014), “Do We Really Value Identified Lives More Highly Than Statistical Lives?," Medical Decision Making 34 (5): 556-559.

Schelling T.C. (1984), "The Life You Save May Be Your Own," [in:] T.C. Schelling, Choice and Consequence, Harvard University Press, Cambridge, MA: 113-146.

Tännsjö T. (2019), Setting Health-Care Priorities: What Ethical Theories Tell Us, Oxford University Press, Oxford.

Tribe L.H. (1971), "Trial by Mathematics: Precision and Ritual in the Legal Process," Harvard Law Review 84: 1329-1393.

Waldron J. (2012), Dignity, Rank and Rights, Oxford University Press, Oxford.

Walzer J. (1983), Spheres of Justice, Basic Books, New York.

Weinrib E.J. (1980), “The Case for a Duty to Rescue," Yale Law Journal 90 (2): 247-293.

World Health Organization (WHO) (2001), The World Health Report 2001: Mental Health: New Understanding, New Hope, WHO, Geneva. 